\title{
Cervical radiculopathy: is a prosthesis preferred over fusion surgery? A systematic review
}

\author{
Caroline M. W. Goedmakers ${ }^{1}$ (D) Tessa Janssen ${ }^{1} \cdot$ Xiaoyu Yang $^{1} \cdot$ Mark P. Arts $^{2} \cdot$ Ronald H. M. A. Bartels $^{3}$. \\ Carmen L. A. Vleggeert-Lankamp ${ }^{1}$
}

Received: 14 February 2019 / Revised: 17 July 2019 / Accepted: 5 October 2019 / Published online: 22 October 2019

(c) The Author(s) 2019

\begin{abstract}
Background Meta-analyses on the comparison between fusion and prosthesis in the treatment of cervical radiculopathy mainly analyse studies including mixed patient populations: patients with radiculopathy with and without myelopathy. The outcome for patients with myelopathy is different compared to those without. Furthermore, apart from decompression of the spinal cord, restriction of motion is one of the cornerstones of the surgical treatment of spondylotic myelopathy. From this point of view, the results for arthroplasty might be suboptimal for this category of patients. Comparing clinical outcome in patients exclusively suffering from radiculopathy is therefore a more valid method to compare the true clinical effect of the prosthesis to that of fusion surgery.

Aim The objective of this study was to compare clinical outcome of cervical arthroplasty (ACDA) to the clinical outcome of fusion (ACDF) after anterior cervical discectomy in patients exclusively suffering from radiculopathy, and to evaluate differences with mixed patient populations.

Methods A literature search was completed in PubMed, EMBASE, Web of Science, COCHRANE, CENTRAL and CINAHL using a sensitive search strategy. Studies were selected by predefined selection criteria (i.a.) patients exclusively suffering from cervical radiculopathy), and risk of bias was assessed using a validated Cochrane Checklist adjusted for this purpose. An additional overview of results was added from articles considering a mix of patients suffering from myelopathy with or without radiculopathy.

Results Eight studies were included that exclusively compared intervertebral devices in radiculopathy patients. Additionally, 29 articles concerning patients with myelopathy with or without radiculopathy were studied in a separate results table. All articles showed intermediate to high risk of bias. There was neither a difference in decrease in mean NDI score between the prosthesis (20.6 points) and the fusion (20.3 points) group, nor was there a clinically important difference in neck pain (VAS). Comparing these data to the mixed population data demonstrated comparable mean values, except for the 2-year follow-up NDI values in the prosthesis group: mixed group patients that received a prosthesis reported a mean NDI score
\end{abstract}

Electronic supplementary material The online version of this article (https://doi.org/10.1007/s00586-019-06175-y) contains supplementary material, which is available to authorized users.

Caroline M. W. Goedmakers

C.M.W.Goedmakers@lumc.nl

Tessa Janssen

T.M.H.Janssen@1umc.nl

Xiaoyu Yang

X.Yang@lumc.nl

Mark P. Arts

m.arts@haaglandenmc.nl

Ronald H. M. A. Bartels

Ronald.Bartels@radboudumc.nl

Carmen L. A. Vleggeert-Lankamp

C.L.A.Vleggeert-Lankamp@lumc.nl
1 Department of Neurosurgery, Leiden University Medical Centre, Leiden, Stafsecretariaat Neurochirurgie, Postzone J11-R-83, Postbus 9600, 2300 RC Leiden, The Netherlands

2 Department of Neurosurgery, The Hague Medical Centre, The Hague, Afdeling Neurochirurgie, Postbus 432, 2501 CK Den Haag, The Netherlands

3 Department of Neurosurgery, Radboud University Medical Centre, Nijmegen Afdeling Neurochirurgie, Huispostnummer 943, Prof. R.H.M.A. Bartels, Postbus 9101, 6500 HB Nijmegen, The Netherlands 
of 15.6, indicating better clinical outcome than the radiculopathy patients that received a prosthesis though not reaching clinical importance.

Conclusions ACDF and ACDA are comparably effective in treating cervical radiculopathy due to a herniated disc in radiculopathy patients. Comparing the 8 radiculopathy with the 29 mixed population studies demonstrated that no clinically relevant differences were present in clinical outcome between the two types of patients.

\section{Graphic abstract}

These slides can be retrieved under Electronic Supplementary Material.
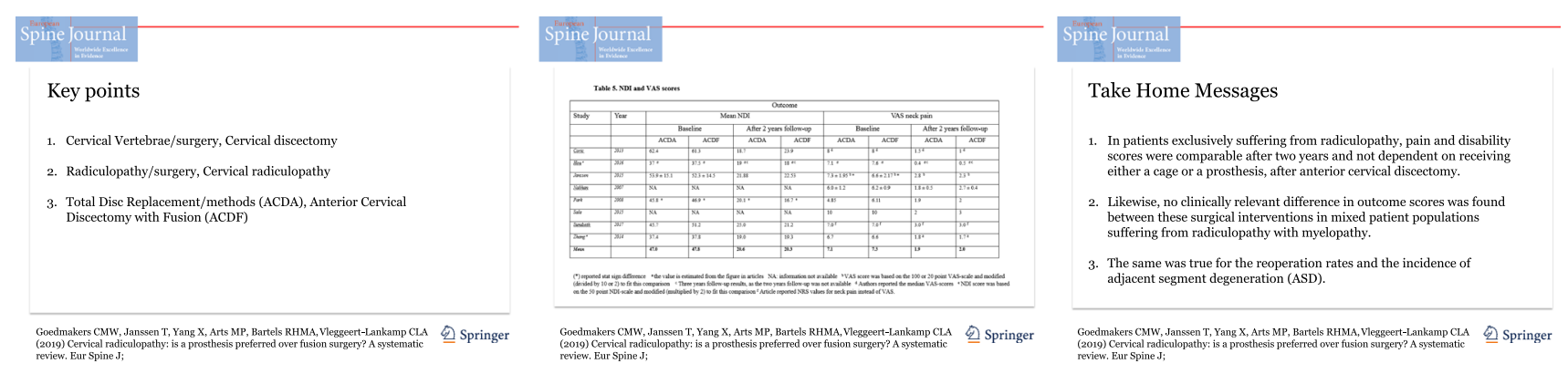

Keywords Cervical spine · Total disc replacement · Anterior cervical discectomy fusion $\cdot$ Clinical outcome $\cdot$ Visual Analogue Scale $\cdot$ Neck Disability Index

\section{Introduction}

Anterior cervical discectomy with fusion (ACDF) is considered the standard surgical treatment for cervical radiculopathy. Decompressing the nerve root aims to diminish radicular complaints and adding a cage to the intervertebral space aims to maintain foraminal height and cervical alignment [1-3]. In the past three decades, the use of a disc prosthesis (ACDA) is being investigated as an alternative treatment for patients with symptomatic cervical radiculopathy caused by cervical disc herniation. The rationale for the use of a prosthesis is to avoid loss of motion at the target level, which is a consequence of treating radiculopathy with ACDF. It is hypothesized that loss of motion causes neck disability and increased mechanical stress at the adjacent levels, possibly causing acceleration of degeneration at these adjacent segments (adjacent segment degeneration; ASD) [4, 5].

Comparing the results of ACDF and ACDA has been done before in systematic reviews and meta-analyses. An overview of Bartels et al. (2017) considered 21 meta-analyses in which the included studies tended to conclude that ACDA gave a better outcome, but differences were small and not clinically relevant [6]. However, it appeared that the meta-analyses considered mainly randomized controlled trials (RCTs) that were performed on mixed patient populations: patients suffering from primarily radiculopathy and patients suffering from primarily myelopathy.

Myelopathy is presumed to be generally occurring in another type of patient, namely the patient with the more degenerated spine. Implanting a prosthesis in these patients may not lead to the optimal effect that is aimed for by implanting a prosthesis. Comparing the outcome of fusion versus prosthesis in patients that primarily suffer form myelopathy may therefore have a different outcome than evaluation of outcome in patients that suffer primarily from radiculopathy.

In this review, only studies that discuss clinical findings in patients with primary complaints of radiculopathy, excluding those suffering primarily from myelopathy, are evaluated. Additionally, outcome of these findings will be compared to clinical outcome reported in the articles considered in the meta-analyses that evaluate mixed patient populations.

\section{Materials and methods}

\section{Literature search strategy}

The initial literature search strategy was performed in PubMed, EMBASE, Web of Science, COCHRANE, CENTRAL and CINAHL on 2 August 2016, and all English- and Chinese-language publications on the comparison of ACDF and ACDA were retrieved. Two of the authors separately evaluated the articles by title, abstract or full text, when necessary, to select the studies that met the predefined selection criteria. One author translated two relevant articles from Chinese to English. The search strategies used in the different databases were based on the search string as shown in Fig. 1.

Article selection was based upon the following criteria: 
Fig. 1 Search strategy. Search strategy that was used to perform the literature search 2 August 2016
("Cervical Vertebrae"[mesh] OR "Cervic"[tw] OR "cervical"[tw] OR "neck"[mesh] OR "neck"[tw]) AND ("Intervertebral Disc Displacement"[mesh] OR "Slipped disk"[tw] OR "Slipped disks"[tw] OR "Slipped disc"[tw] OR "Slipped discs"[tw] OR "Prolapsed disk"[tw] OR "Prolapsed disks"[tw] OR "Prolapsed disc"[tw] OR "Prolapsed discs"[tw] OR "Herniated disk"[tw] OR "Herniated disks"[tw] OR "Herniated disc"[tw] OR "Herniated discs"[tw] OR "hernia"[tw] OR "Disc Displacement"[tw] OR "Disc Displacements"[tw] OR "Disk Displacement"[tw] OR "Disk Displacements"[tw] ] OR "displaced disk"[tw] OR "displaced disks"[tw] OR "displaced disc"[tw] OR "displaced discs"[tw] OR "Radiculopathy"[Mesh] OR "Radiculopathies"[tw] OR "Radiculopathy, Cervical"[tw] OR "Cervical Radiculopathies"[tw] OR "Cervical Radiculopathy"[tw] OR "Radiculopathies, Cervical"[tw] OR "Radicular pain"[tw])

\section{AND}

("Diskectomy"[mesh] OR "Diskectomy"[tw] OR "Diskectomies"[tw] OR "Discectomy"[tw] OR "Discectomies"[tw] OR "Surgical Procedures, Operative"[mesh] OR "Surgical"[tw] OR "Operative"[tw] OR "Operation"[tw] OR "Operations"[tw] OR "Foraminotomy"[mesh] OR "Foraminotomy"[tw] OR "surgery"[subheading] OR "surgery"[tw] OR "surgic"[tw])

\begin{abstract}
AND
("Diskectomy"[mesh] OR "Diskectomy"[tw] OR "Diskectomies"[tw] OR "Discectomy"[tw] OR "Discectomies"[tw] OR "Surgical Procedures, Operative"[mesh] OR "Surgical"[tw] OR "Operative"[tw] OR "Operation"[tw] OR "Operations"[tw] OR "Foraminotomy"[mesh] OR "Foraminotomy"[tw] OR "surgery"[subheading] OR "surgery"[tw] OR "surgic"[tw]) AND ('prosthesis' OR “artificial disc” OR 'artificial disk')
\end{abstract}

\begin{abstract}
AND
(randomized controlled trial OR controlled clinical trial OR randomized controlled trials OR random allocation OR double-blind method OR single-blind method OR clinical trial OR clinical trials OR "clinical trial" OR ((singl* OR doubl* OR trebl* OR tripl*) AND (mask* OR blind*)) OR "latin square" OR placebos OR placebo* OR random* OR "Research Design"[MeSH:noexp] OR comparative study OR evaluation studies OR follow-up studies OR prospective studies OR cross-over studies OR control* OR controlled* OR prospective* OR volunteer* OR randomised controlled trial OR randomised controlled trials OR randomized active control trials OR randomized active control trial OR randomised active control trials OR randomised active control trial OR "RaCT" OR "RaCTs" OR RCT OR RCTs OR control*[tw] OR "latin square" [tw] OR cross-over studies [mh] OR control[tw] OR "Evaluation Studies "[Publication Type] OR "Evaluation Studies as Topic"[Mesh] OR "Pragmatic Clinical Trial" OR "Pragmatic Clinical Trials")
\end{abstract}

- The study compares ACDF to ACDA in one-level anterior discectomy.

- The study includes at least twenty patients in each treatment arm.

- The study provides follow-up data for at least 2 years.

- The study measures primary or secondary outcome in either the Neck Disability Index (NDI) or Visual Analogue Scale neck pain (VAS neck pain).

- The study only includes patients suffering from radiculopathy, excluding patients suffering from myelopathy.

- The article is not a meeting abstract.

Any discrepancy in selection between the reviewers was resolved in open discussion, and, if needed, a third reviewer was asked to make a final decision. Reference screening and citation tracking were performed on the identified articles (Fig. 2).

When the literature search was repeated in August 2017, a meta-analysis by Bartels et al. was found [6].
In this study, 21 meta-analyses were evaluated that focused on the outcomes of one-level arthroplasty. The included meta-analyses primarily described studies that allowed inclusion of patients suffering from cervical myelopathy. In order to be complete in our overview, the studies described in the meta-analyses were evaluated additionally in separate mixed group tables. This systematic review was conducted in accordance with the Preferred Reporting Items for Systematic Reviews and Meta-Analyses: the PRISMA Statement [7] (Fig. 3).

\section{Quality assessment}

The methodological quality of all studies (including those from the RCTs describing mixed populations) was assessed by three independent reviewers (XY, TJ, CG), using an adjusted version of the checklist for cohort studies of 
Fig. 2 Flow chart of article selection process radiculopathy articles. Flow chart describing the search process for the articles exclusively including patients suffering from cervical radiculopathy

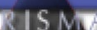

S MNA

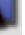

PRISMA 2009 Flow Diagram

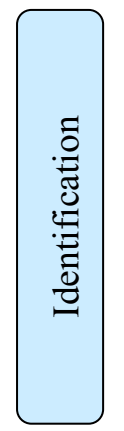

Records identified through database searching $(\mathrm{n}=603)$

Additional records identified through other sources $(\mathrm{n}=0)$
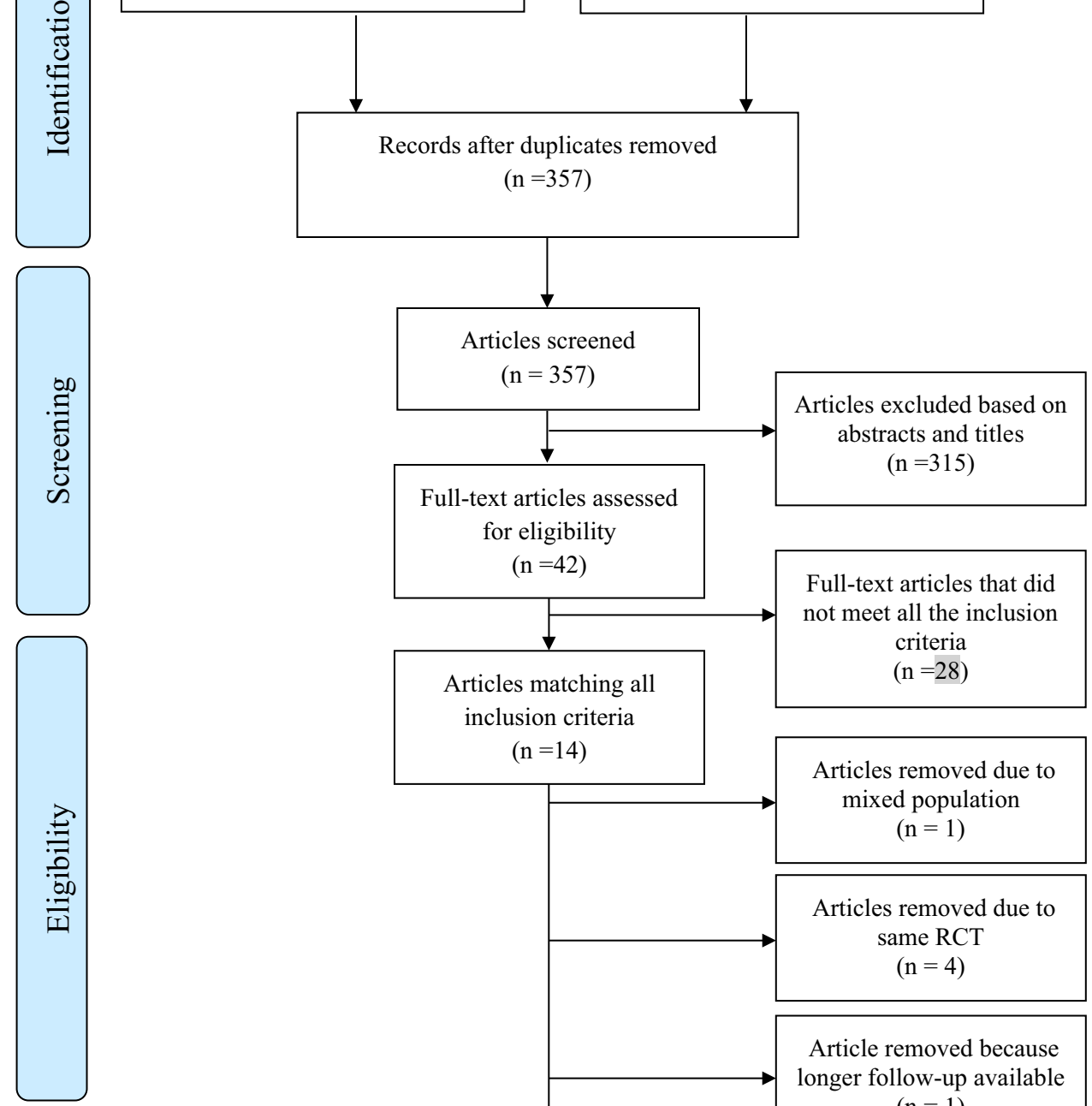
inclusion criteria
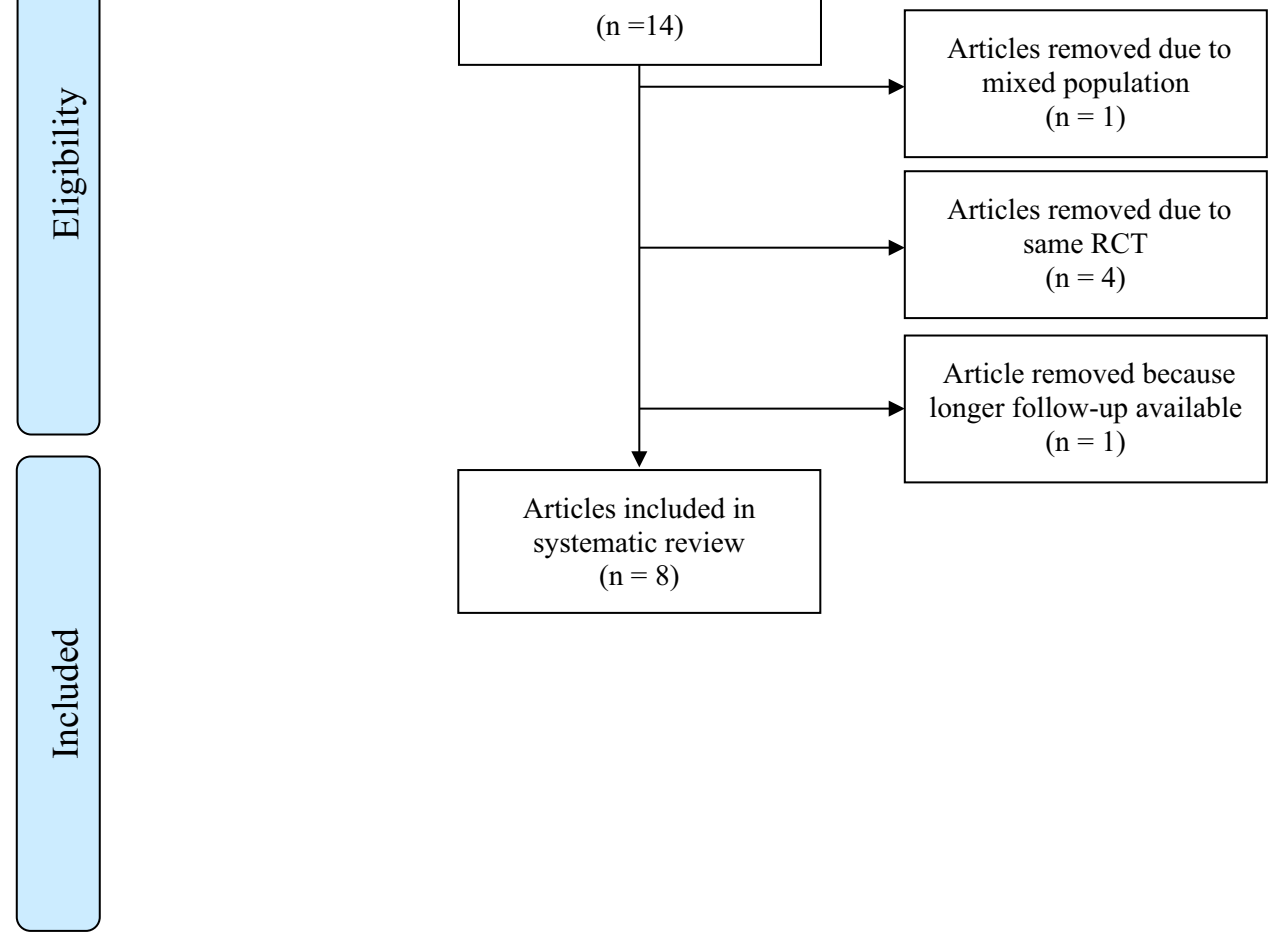

Articles included in systematic review $(\mathrm{n}=8)$ the Dutch Cochrane Center [8]. If there was no consensus about the assessment, a fourth reviewer (CVL) was consulted.
Studies could be maximally awarded 9 points. Studies were then divided into low (7-9 points), intermediate (5-6 points) or high (4 or less points) risk of bias. 
Fig. 3 Flow chart of article selection process mixed group articles. Flow chart describing the search process for the articles including patients suffering from cervical myelopathy with or without radiculopathy

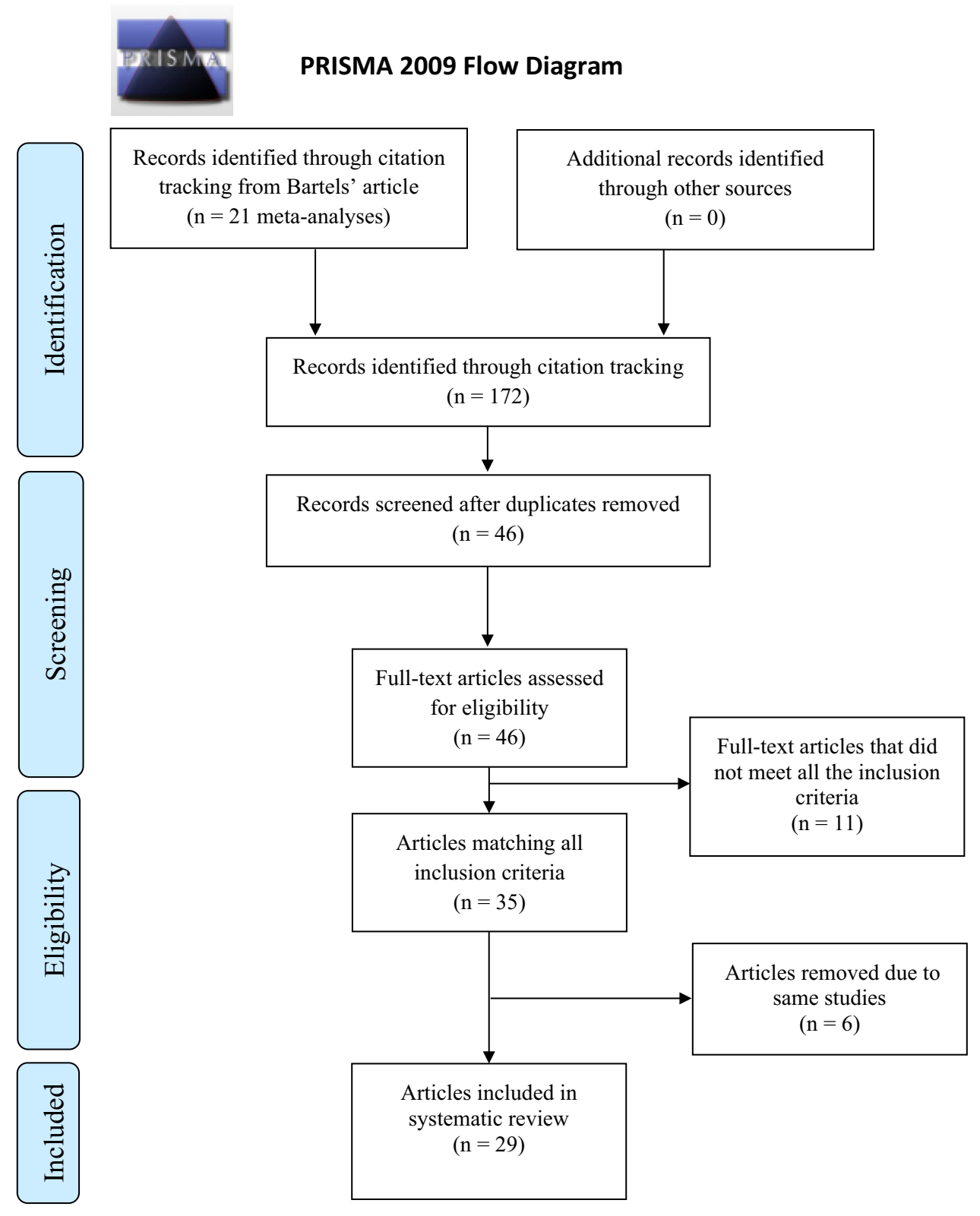

\section{Outcome measures}

For matters of comparison, the most frequently used outcome parameters were extracted in this systematic review: the Neck Disability Index (NDI) and the Visual Analogue Scale (VAS) for neck pain. In addition, data on reoperations and complications were collected.

The NDI is a ten-item scaled questionnaire on three different aspects of neck complaints: pain intensity, dailywork-related and non-work-related activities. Each item is scored from 0 to 5 , and the raw total score ranges from 0 (best score) to 50 (worst score) [10]. Several studies indicate a MCID for NDI of 20 points on a 100-point scale $[11,12]$.
As many authors choose to present NDI scores on a 100point scale, the outcome scores in this article were converted to that scale.

The Visual Analogue Scale (VAS) is the most commonly used tool to assess pain intensity. $0 \mathrm{~mm}$ indicates 'no pain' and $100 \mathrm{~mm}$ indicates the 'worst pain imaginable'. According to the literature, the minimal clinical important difference (MCID) is approximately $20 \mathrm{~mm}$, or 2.0 on a ten-point scale [9]. As most articles presented the VAS scores ranging from 0 to 10 , we chose to convert all VAS scores to that scale in order to properly analyse and compare the data. If articles reported the NRS scores for neck pain instead of the VAS, articles were nevertheless considered eligible for inclusion because the two scales are very similar. 
After performing the systematic literature review, it will be evaluated whether data can be pooled and if heterogeneity (using $I^{2}$ ) can be calculated.

\section{Level of evidence}

The quality of evidence for all outcome parameters was evaluated using the GRADE (Grading of Recommendations Assessment, Development and Evaluation) approach according to Atkins [13] and adapted from Furlan [14].

\section{Results}

\section{Search results and study selection of studies describing radiculopathy patients}

A total of 603 articles were identified, of which 357 original articles remained after removing duplicates. Titles and abstracts were screened, resulting in 42 eligible articles. These articles were read full-text, and 14 studies met all inclusion criteria. Six articles were additionally excluded after meticulously investigating the literature. The article from Burkus et al. [15] had to be excluded because it also contained patients suffering from myelopathy. The article reports on the 7-year results of a study comparing ACDF versus prosthesis. The study population seemed to consist of patients with only radiculopathy. However, while searching for earlier follow-up results from this study, the article describing the 2-year follow-up results of this population was found [16]. From that particular article, it was clear that the study population was a mixed one, also including patients with myelopathy and therefore Burkus' article was excluded.

Five of the remaining 12 studies concerned the same RCT comparing Prodisc-C versus ACDF (autograft bone and plate). Therefore, the four studies with shorter followup time were excluded (one with 2-year, one with 4-year, one with 5-year and one with 7-year follow-up results) [17-20]. We decided to only include the article describing the 7-year results (the longest follow-up period) without the continued access group [21].

Additionally, one more study was excluded since it described the 1-year follow-up results [22], while the 3 -year follow-up results [23] were also available; eight studies remained that fulfilled all inclusion criteria.

Two RCTs described results on the Mobi-C prosthesis in comparison with ACDF methods using autograft alone [24] and securing with a plate [25]. Additionally, there was one retrospective study (Mobi-C vs PEEK cage without plate) [26] and one prospective cohort study comparing different types of prostheses (Prestige ST, Bryan, ProdiscC) [27] versus ACDF (PEEK cage without plate). Two other RCTs compared the Prodisc-C prosthesis to ACDF with plate fixation $[21,23]$, and one RCT compared the Bryan prosthesis or KineflexIC to ACDF with plate [28]. Lastly, one article described the comparison between the Discover prosthesis and a PEEK cage without plate [29].

The mean number of patients per group in the 8 included trials was 48 . The mean age of the patients was 44.7 (ACDA) and 45.4 (ACDF) years, and the percentage of male patients was $46.1 \%$ (ACDA) and $49.0 \%$ (ACDF) (Table 1).

Table 1 Study demographics radiculopathy studies

\begin{tabular}{|c|c|c|c|c|c|c|c|c|c|}
\hline \multirow[t]{2}{*}{ References } & \multirow[t]{2}{*}{ Study design } & \multirow[t]{2}{*}{ Prosthetic device } & \multicolumn{2}{|c|}{$\begin{array}{l}\text { Number of par- } \\
\text { ticipants }\end{array}$} & \multicolumn{2}{|c|}{ Age $($ mean $\pm S D)$} & \multicolumn{2}{|c|}{ Men (\%) } & \multirow{2}{*}{$\begin{array}{l}\text { Follow- } \\
\text { up } \\
\text { (years) }\end{array}$} \\
\hline & & & ACDA & $\mathrm{ACDF}$ & ACDA & $\mathrm{ACDF}$ & ACDA & $\mathrm{ACDF}$ & \\
\hline Coric [28] & RCT & Bryan, Kineflex|C & 41 & 32 & 49.5 & 49.3 & 39 & 44 & 5 \\
\hline Hou [24] & RCT & Mobi-C & 51 & 48 & $46.3 \pm 7.8$ & $48.5 \pm 8.3$ & 58.8 & 58.3 & 5 \\
\hline Janssen [21] & RCT & ProDisc-C & 103 & 106 & $42.1 \pm 8.42$ & $43.5 \pm 7.15$ & 45 & 46 & 7 \\
\hline Nabhan [23] & RCT & ProDisc-C & $21^{\dagger}$ & $20^{\dagger}$ & $44^{\mathrm{a}}$ & $44^{\mathrm{a}}$ & $56.1^{\mathrm{a}}$ & $56.1^{\mathrm{a}}$ & 3 \\
\hline Park [26] & Retrospective & Mobi-C & 21 & 32 & 45 & 47 & 52.4 & 62.5 & 1 \\
\hline Sala [27] & Prospective cohort study & $\begin{array}{l}\text { Prestige ST, Bryan } \\
\text { or ProDisc-C }\end{array}$ & 28 & 27 & 41 & 41 & 25 & 33.3 & 2 \\
\hline Sundseth [29] & RCT & Discover & 68 & 68 & 44.7 & 43.4 & 47.1 & 45.6 & 2 \\
\hline Zhang [25] & $\mathrm{RCT}$ & Mobi-C & 55 & 56 & 44.8 & 46.7 & 45.5 & 46.4 & 4 \\
\hline
\end{tabular}

Year of publication, study type, prosthesis type, number of patients in each group, mean age for each treatment group, percentage of males and the follow-up period represented for the studies exclusively including patients suffering from cervical radiculopathy

$S D$ standard deviation, $A C D A$ anterior cervical discectomy with arthroplasty, $A C D F$ anterior cervical discectomy and fusion, $N A$ not available

${ }^{a}$ Mean value for all participants

${ }^{\dagger} 1$ patients in total, division between groups not clear 


\section{Search results and study selection of studies describing mixed patient groups}

From the 21 meta-analyses retrieved from Bartels' article, 172 articles were found eligible for screening and after duplicates were removed 46 remained for full-text assessment. One article was selected for analysis in the radiculopathy group, as it described a population of patients from which myelopathy patients were excluded. Ten other articles were excluded because they did not report on the relevant clinical outcome measures or solely on radiological outcome parameters. Lastly, from the 35 articles that matched all inclusion criteria six articles had to be removed because they reported on the same RCTs, in which case we chose to include the article describing the longest follow-up period. Finally, 29 articles were found eligible for the mixed group overview, all reporting on the comparison between ACDA and ACDF in patients suffering from myelopathy with or without radiculopathy [15, 30-57].

In the 29 included articles, the mean follow-up period was 3 years, mean number of patients per group was 90 (ACDA) and 78 (ACDF), and the mean age 45 (ACDA) and 46 (ACDF) years. Study characteristics for each individual study can be found in Table 2 .

Table 2 Study demographics mixed population studies

\begin{tabular}{|c|c|c|c|c|c|c|c|}
\hline \multirow[t]{2}{*}{ References } & \multirow[t]{2}{*}{ Study design } & \multirow[t]{2}{*}{ Prosthetic device } & \multirow[t]{2}{*}{$\begin{array}{l}\text { Follow-up } \\
\text { (years) }\end{array}$} & \multicolumn{2}{|c|}{$\begin{array}{l}\text { Number of partici- } \\
\text { pants }\end{array}$} & \multicolumn{2}{|c|}{ Age $($ mean $\pm S D)$} \\
\hline & & & & ACDA & $\mathrm{ACDF}$ & ACDA & $\mathrm{ACDF}$ \\
\hline Burkus [15] & RCT & Prestige ST & 7 & 276 & 265 & 43.3 & 43.9 \\
\hline Cheng [30] & RCT & Bryan & 3 & 41 & 42 & $47.2 \pm 5.7$ & $47.7 \pm 5.8$ \\
\hline Coric $[31]$ & RCT & Bryan & 1 & 17 & 16 & 43 & 43 \\
\hline Coric [32] & RCT & Bryan, Kineflex|C, Discover & 2 & 57 & 41 & 46.6 & 46.3 \\
\hline Coric [33] & RCT & Kineflex|C & 2 & 136 & 133 & $43.7 \pm 7.76$ & $43.9 \pm 7.39$ \\
\hline Davis [34] & RCT & Mobi-C & 4 & 225 & 105 & $45.3 \pm 8.1$ & $46.2 \pm 8.0$ \\
\hline Ding [35] & Prospective cohort study & Prestige LP & 2 & 40 & 38 & 40 & 38 \\
\hline Fay [36] & Prospective cohort study & Bryan & 2 & 37 & 40 & $52.1 \pm 9.1 *$ & $63.0 \pm 10.6 *$ \\
\hline Garrido [37] & RCT & Bryan & 4 & 21 & 26 & 40 & 43.3 \\
\hline Gornet [38] & Prospective cohort study & Prestige LP & 7 & 280 & 265 & $44.5 \pm 8.8$ & $43.9 \pm 8.8$ \\
\hline Grasso [39] & Prospective cohort study & Prodisc-C, Mobi-C & 2 & 20 & 20 & 40.5 & 47.3 \\
\hline Hisey [40] & RCT & Mobi-C & 5 & 164 & 81 & NA & NA \\
\hline Hou [41] & Prospective cohort study & Discover & 2 & 117 & 108 & 45.6 & 44.1 \\
\hline Hacker [42] & RCT & Bryan & 1 & 22 & 24 & NA & NA \\
\hline Jawahar [43] & RCT & $\begin{array}{l}\text { Kineflex|C, Mobi-C, Advent } \\
\text { Cervical Disc }\end{array}$ & 4 & 59 & 34 & NA & NA \\
\hline Kim [44] & Prospective cohort study & Bryan & 1 & 39 & 26 & 43.6 & 47.4 \\
\hline $\operatorname{Li}[44]$ & Prospective cohort study & DCI & 2 & 39 & 42 & $45.3 \pm 8.6$ & $49.5 \pm 9.3$ \\
\hline Phillips [46] & RCT & PCM & 5 & 218 & 185 & $45.3 \pm 9.0$ & $43.7 \pm 8.3$ \\
\hline Porchet [47] & RCT & Prestige II & 2 & 27 & 28 & $44 \pm 8.9$ & $43 \pm 6.9$ \\
\hline \multirow[t]{2}{*}{ Riew [48] } & Prospective cohort study & Prestige ST & 2 & 59 & 52 & $53.5 \pm 13.9$ & $53.5 \pm 16.9$ \\
\hline & & Bryan & & 47 & 41 & $52.0 \pm 14.6$ & $50.8 \pm 18.8$ \\
\hline Riina [49] & RCT & Prestige ST & 2 & 10 & 9 & $40.8 \pm 8.8$ & $38.1 \pm 4.9$ \\
\hline Rožanković [50] & RCT & Discover & 2 & 51 & 50 & $41.32 \pm 8.80$ & $41.94 \pm 9.36$ \\
\hline Sasso [51] & RCT & Bryan & 2 & 56 & 59 & $42.5 \pm 7.8$ & $46.1 \pm 7.8$ \\
\hline Sasso [52] & RCT & Bryan & 4 & 242 & 221 & 44.4 & 44.7 \\
\hline Steinmetz [53] & RCT & Bryan, Prestige ST & 2 & 47 & 46 & $44.3 \pm 6.5$ & $43.9 \pm 8.3$ \\
\hline Vaccaro [54] & RCT & SECURE-C & 2 & 151 & 140 & $43.4 \pm 7.50$ & $44.4 \pm 7.86$ \\
\hline Wang [55] & RCT & Bryan & 2 & 28 & 31 & 42 & 43 \\
\hline Yan [56] & Prospective cohort study & Bryan & 8 & 29 & 39 & $48.83 \pm 6.70$ & $48.72 \pm 7.33$ \\
\hline Zhang [57] & RCT & Bryan & 2 & 60 & 60 & $44.77 \pm 5.60$ & $45.57 \pm 5.83$ \\
\hline
\end{tabular}

Year of publication, prosthesis type, the follow-up period, number of patients in each group and the mean age for each treatment group represented for the studies including patients suffering from both cervical radiculopathy and/or myelopathy

*Reported statistical significant difference 


\section{Quality assessment}

\section{Quality assessment in radiculopathy studies}

Only one article scored 7 out of 9 points, illustrating a low risk of bias [29], four articles scored five points [21, $24,27,28]$ and one scored 4 points [23] all indicating an intermediate risk of bias. The two remaining articles scored three points illustrating a high risk of bias $[25$, 26] (Table 3).

\section{Quality assessment in mixed studies}

From the 29 studies, there were two with a low risk of bias $[36,41], 21$ with an intermediate risk of bias $[15,30,31$, $33-35,38-40,42-50,54,55,57]$ and six with a high risk of bias $[32,37,51-53,56]$ (Table 4).

\section{Clinical outcome}

\section{Neck Disability Index (NDI)}

\section{Disability in articles describing exclusively radiculopathy patients}

Six articles use the NDI as a scale to report on functionality [21, 24-26, 28, 29] (Table 5). All articles show a significant improvement in post-operative functionality compared to baseline, for both treatment groups. However, only one article shows a significant difference in NDI between the two treatment groups after 2 years. Though the reported statistically significant difference in that article is not clinically relevant, it shows a more favourable outcome for fusion, as compared to the prosthesis [29].

\section{Level of evidence}

The level of evidence is lowered by two levels, since most studies have an intermediate to high risk of bias. Furthermore, the findings are inconsistent as only one article presented a significant difference between the two groups, while the 5 other articles did not. Additionally, only one article succeeded in precisely stating the standard deviation (SD), but only for the baseline NDI estimate [21]. Three other articles provided information from which the SD could be calculated [24, 25, 29], while the remaining four did not [23, 26-28]. Therefore, the level of evidence that there is no difference in NDI improvement after 2-year follow-up in radiculopathy patients is low.

\section{Functionality in articles describing mixed patient populations}

Twenty-six articles use the NDI as an outcome parameter at baseline, and after 2 years, three articles do not $[31,35$, 42]. Five articles report a statistical significant difference between ACDF and ACDA 2 years after surgery in favour of the prosthesis, and the difference is, however, never exceeding the MCID of 20 . In contrast to the vast majority of articles, three studies show a small difference in favour of fusion, though not statistically significant $[44,55,56]$.

\section{Level of evidence}

The level of evidence is lowered by 3 levels. Findings are inconsistent, risk of bias is intermediate to high, and data are not reported sufficiently precise. Additionally, the vast majority of studies received industry sponsoring and authors reported extensive disclosures, which enlarges the probability of reporting bias. Therefore, the level of evidence that there is no difference in NDI improvement after 2-years follow-up in mixed population patients is very low.
Table 3 Risk of bias for the radiculopathy studies

\begin{tabular}{llllll}
\hline References & $\begin{array}{l}\text { Total risk of } \\
\text { bias score }\end{array}$ & $\begin{array}{l}\text { Well-defined patient } \\
\text { group and study goal }\end{array}$ & $\begin{array}{l}\text { Outcome prop- } \\
\text { erly examined }\end{array}$ & $\begin{array}{l}\text { Absence of } \\
\text { selection bias }\end{array}$ & $\begin{array}{l}\text { Absence of } \\
\text { attribution } \\
\text { bias }\end{array}$ \\
\hline Coric [28] & $5 *$ & $* *$ & $*$ & $*$ & $* *$ \\
Hou [24] & $5 *$ & $* *$ & $*$ & $*$ & $*$ \\
Janssen [21] & $5 *$ & $* *$ & $*$ & $*$ & $*$ \\
Nabhan [23] & $4 *$ & $* *$ & & $*$ & $*$ \\
Park [26] & $3 *$ & $* *$ & $*$ & $*$ & $*$ \\
Sala [27] & $5 *$ & $* *$ & $*$ & $*$ & \\
Sundseth [29] & $7 *$ & $* * *$ & $* *$ & $*$ & $*$ \\
Zhang [25] & $3 *$ & $* *$ & & & \\
\hline
\end{tabular}

The risk-of-bias analysis is represented in number of stars ('*'); the higher the number of stars, the lower the risk of bias for each radiculopathy study 
Table 4 Risk of bias for mixed group studies

\begin{tabular}{|c|c|c|c|c|c|}
\hline References & $\begin{array}{l}\text { Total risk-of- } \\
\text { bias score }\end{array}$ & $\begin{array}{l}\text { Patient group } \\
\text { and study goal }\end{array}$ & $\begin{array}{l}\text { Outcome prop- } \\
\text { erly examined }\end{array}$ & $\begin{array}{l}\text { Absence of } \\
\text { selection bias }\end{array}$ & $\begin{array}{l}\text { Absence of } \\
\text { attribution } \\
\text { bias }\end{array}$ \\
\hline Burkus [15] & $4^{*}$ & $* * *$ & * & - & - \\
\hline Cheng [30] & $5^{*}$ & $* *$ & $* *$ & $*$ & - \\
\hline Coric [31] & $4^{*}$ & $* *$ & $*$ & - & $*$ \\
\hline Coric [32] & $3 *$ & $* *$ & $*$ & - & - \\
\hline Coric [33] & $4^{*}$ & $* * *$ & $*$ & - & - \\
\hline Davis [34] & $5^{*}$ & $* * *$ & $*$ & - & $*$ \\
\hline Ding [35] & $4^{*}$ & $* *$ & $*$ & - & $*$ \\
\hline Fay [36] & $7 *$ & $* * *$ & $* *$ & $*$ & $*$ \\
\hline Garrido [37] & $2 *$ & $* *$ & - & - & - \\
\hline Gornet [38] & $4 *$ & $* * *$ & * & - & - \\
\hline Grasso [39] & $5^{*}$ & $* * *$ & * & - & * \\
\hline Hisey [40] & $4^{*}$ & $* *$ & $*$ & - & $*$ \\
\hline Hou [41] & $7 *$ & $* * *$ & $* *$ & - & $* *$ \\
\hline Hacker [42] & $4^{*}$ & $* *$ & $*$ & - & $*$ \\
\hline Jawahar [43] & $6^{*}$ & $* *$ & $* *$ & $*$ & * \\
\hline Kim [44] & $5^{*}$ & $* *$ & $* *$ & - & $*$ \\
\hline $\operatorname{Li}[44]$ & $6^{*}$ & $* *$ & $* *$ & - & $* *$ \\
\hline Phillips [46] & $4^{*}$ & $* * *$ & * & - & - \\
\hline Porchet [47] & $6^{*}$ & $* * *$ & $*$ & $*$ & $*$ \\
\hline Riew [48] & $6^{*}$ & $* * *$ & $* *$ & - & * \\
\hline Riina [49] & $4^{*}$ & $* *$ & $*$ & - & $*$ \\
\hline Rožanković [50] & $4^{*}$ & $* *$ & * & $*$ & - \\
\hline Sasso [51] & $3 *$ & $* *$ & $*$ & - & - \\
\hline Sasso [52] & $2 *$ & $* *$ & - & - & - \\
\hline Steinmetz [53] & $2 *$ & $* *$ & - & - & - \\
\hline Vaccaro [54] & $4^{*}$ & $* * *$ & - & - & $*$ \\
\hline Wang [55] & $4^{*}$ & $* *$ & $*$ & - & $*$ \\
\hline Yan [56] & $3^{*}$ & $* *$ & $*$ & - & - \\
\hline Zhang [57] & $5^{*}$ & $* * *$ & $* *$ & - & - \\
\hline
\end{tabular}

The risk-of-bias analysis is represented in number of stars ('*'); the higher the number of stars, the lower the risk of bias for each mixed group study

\section{Visual Analogue Scale (VAS) neck pain}

\section{VAS neck pain in articles describing exclusively radiculopathy patients}

Seven of the eight articles used the VAS to grade neck pain, and one article used the NRS score [29]. All articles showed that post-operative pain improved compared to baseline (Table 5). None of the articles demonstrated a statistically significant difference between the ACDA and ACDF group after 2 years.

\section{Level of evidence}

The level of evidence is lowered by 1 level, since most studies have an intermediate to high risk of bias. Moreover, only one study reports the exact standard deviations with every estimate [23]. Therefore, the level of evidence is moderate that there is no difference in neck pain improvement after implanting a cage or a prosthesis in cervical radiculopathy patients.

\section{VAS neck pain in articles describing mixed patient populations}

Twenty-four articles out of the 29 articles use the VAS neck pain as an outcome measure. All articles showed that neck pain improved post-operatively in comparison with baseline, in both treatment groups. Four articles report a statistically significant difference between the prosthesis and fusion in favour of the prosthesis $[46,50,51,57]$ (Table 6). 
Table 5 NDI and VAS outcome tables for radiculopathy studies

\begin{tabular}{|c|c|c|c|c|c|c|c|c|}
\hline \multicolumn{9}{|l|}{ Outcome } \\
\hline \multirow[t]{3}{*}{ References } & \multicolumn{4}{|l|}{ Mean NDI } & \multicolumn{4}{|c|}{ VAS neck pain } \\
\hline & \multicolumn{2}{|l|}{ Baseline } & \multicolumn{2}{|c|}{$\begin{array}{l}\text { After 2-year } \\
\text { follow-up }\end{array}$} & \multicolumn{2}{|l|}{ Baseline } & \multicolumn{2}{|c|}{$\begin{array}{l}\text { After 2-year } \\
\text { follow-up }\end{array}$} \\
\hline & ACDA & $\mathrm{ACDF}$ & ACDA & $\mathrm{ACDF}$ & ACDA & $\mathrm{ACDF}$ & ACDA & $\mathrm{ACDF}$ \\
\hline Coric [28] & 62.4 & 61.3 & 18.7 & 23.9 & $8^{\mathrm{d}}$ & $8^{\mathrm{d}}$ & $1.5^{\mathrm{d}}$ & $1^{\mathrm{d}}$ \\
\hline Hou $[24]^{\mathrm{a}}$ & $37^{\mathrm{a}}$ & $37.5^{\mathrm{a}}$ & $19^{\mathrm{a}, \mathrm{c}}$ & $18^{\mathrm{a}, \mathrm{c}}$ & $7.1^{\mathrm{a}}$ & $7.6^{\mathrm{a}}$ & $0.4^{\mathrm{a}, \mathrm{c}}$ & $0.5^{\mathrm{ac}}$ \\
\hline Janssen [21] & $53.9 \pm 15.1$ & $52.3 \pm 14.5$ & 21.88 & 22.53 & $7.3 \pm 1.95^{\mathrm{b}} *$ & $6.6 \pm 2.17^{\mathrm{b}} *$ & $2.8^{\mathrm{b}}$ & $2.3^{\mathrm{b}}$ \\
\hline Nabhan [23] & NA & NA & NA & NA & $6.0 \pm 1.2$ & $6.2 \pm 0.9$ & $1.8 \pm 0.5$ & $2.7 \pm 0.4$ \\
\hline Park [26] & $45.8^{\mathrm{e}}$ & $46.9^{\mathrm{e}}$ & $20.1^{\mathrm{e}}$ & $16.7^{\mathrm{e}}$ & 4.85 & 6.11 & 1.9 & 2 \\
\hline Sala [27] & NA & NA & NA & NA & 10 & 10 & 2 & 3 \\
\hline Sundseth [29] & 45.7 & 51.2 & 25.0 & 21.2 & $7.0^{f}$ & $7.0^{\mathrm{f}}$ & $3.0^{\mathrm{f}}$ & $3.0^{\mathrm{f}}$ \\
\hline Zhang $[25]^{\mathrm{a}}$ & 37.4 & 37.8 & 19.0 & 19.3 & 6.7 & 6.6 & $1.8^{\mathrm{a}}$ & $1.7^{\mathrm{a}}$ \\
\hline
\end{tabular}

NDI (100-point scale) and VAS (10-point) scores at baseline and after 2 years for each study exclusively including patients suffering from cervical radiculopathy

*Reported statistically significant difference

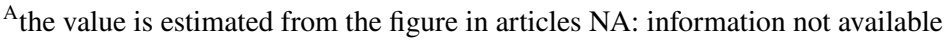

${ }^{\mathrm{b}}$ VAS score was based on the 100- or 20-point VAS and modified (divided by 10 or 2) to fit this comparison

${ }^{c}$ Three-year follow-up results, as the 2-year follow-up was not available

${ }^{\mathrm{d}}$ Authors reported the median VAS scores

${ }^{\mathrm{e}} \mathrm{NDI}$ score was based on the 50-point NDI scale and modified (multiplied by 2) to fit this comparison

${ }^{\mathrm{f}}$ Article reported NRS values for neck pain instead of VAS

\section{Level of evidence}

The level of evidence is lowered with three levels. All articles have an intermediate to high risk of bias, the vast majority of studies received industry sponsoring, and authors reported extensive disclosures, which enlarges the probability of reporting bias. Furthermore, findings are inconsistent and estimates of effect are not sufficiently precise as not all articles state the exact data. Therefore, the level of evidence that there is no difference in neck pain improvement after implanting a cage or a prosthesis in mixed population patients is very low.

\section{Reoperations}

\section{Reoperation rate in articles describing exclusively radiculopathy patients}

Seven of the eight articles reported reoperation rates, of which two articles report statistically significant differences in the rates. One study reports more reoperations in the fusion group [24], and the other higher rates in the prosthesis group [29]. Outcome reporting on the level of reoperation is rather heterogeneous and incomplete; however, the results are suggesting that reoperations are most frequent at the adjacent level for the ACDF group and at the index level for the ACDA group (Table 7).

\section{Reoperation rate in articles describing mixed patient populations}

The majority of the articles report on "subsequent surgical interventions", which include revisions, removals and supplemental fixations. Three of the 29 studies report statistically significant differences between the groups in terms of reoperation rates, all in favour of the arthroplasty group [40, 54].

\section{Complications}

\section{Complications in articles describing exclusively radiculopathy patients}

The most common complications, apart from reoperations, included; adjacent segment disease (ASD), trauma, ongoing neck and/or arm pain, dysphagia, hoarseness, musculoskeletal pain and infections. Complications were seldom permanent. Four articles described adjacent segment disease [21, 23-25], of which only one article described a significantly higher incidence of ASD in ACDF patients [24]. No other statistically significant differences in complication rates were described between the treatment groups. 
Table 6 NDI and VAS outcome tables for mixed group studies

\begin{tabular}{|c|c|c|c|c|c|c|c|c|}
\hline \multicolumn{9}{|l|}{ Outcome } \\
\hline \multirow[t]{3}{*}{ Study } & \multicolumn{4}{|l|}{ Mean NDI } & \multicolumn{4}{|c|}{ VAS neck pain } \\
\hline & \multicolumn{2}{|l|}{ Baseline } & \multicolumn{2}{|c|}{ After 2 years of follow-up } & \multicolumn{2}{|l|}{ Baseline } & \multicolumn{2}{|c|}{ After 2 years of follow-up } \\
\hline & ACDA & ACDF & ACDA & $\mathrm{ACDF}$ & ACDA & ACDF & ACDA & $\mathrm{ACDF}$ \\
\hline Burkus [15] & $55.7 \pm 14.8$ & $56.4 \pm 15.9$ & $20.0 \pm 21.4$ & $22.4 \pm 21.5$ & NA & NA & NA & NA \\
\hline Cheng [30] & $50.6 \pm 6.0$ & $50.1 \pm 5.8$ & $13^{* a}$ & $17^{* a}$ & NA & NA & NA & NA \\
\hline Coric [31] & $42^{\mathrm{a}}$ & $47^{\mathrm{a}}$ & NA & NA & $6.8^{\mathrm{ab}}$ & $6.9^{\mathrm{a} b}$ & NA & NA \\
\hline Coric [32] & 61 & 62 & 19 & 25 & $7.12^{\mathrm{b}}$ & $7.93^{\mathrm{b}}$ & $2.67^{\mathrm{b}}$ & $3.16^{\mathrm{b}}$ \\
\hline Coric [33] & 63.2 & 61.8 & 22.6 & 23.4 & $7.71^{\mathrm{b}}$ & $7.57^{\mathrm{b}}$ & $2.36^{\mathrm{b}}$ & $2.42^{\mathrm{b}}$ \\
\hline Davis [34] & 54 & 56 & $17^{*}$ & $24^{*}$ & $7.1^{\mathrm{ab}}$ & $7.4^{\mathrm{ab}}$ & $1.6^{\mathrm{ab}}$ & $2.0^{\mathrm{a} b}$ \\
\hline Ding [35] & NA & NA & NA & NA & $3.9 \pm 2.5$ & $4.4 \pm 2.7$ & $1.6 \pm 1.0$ & $1.8 \pm 1.0$ \\
\hline Fay [36] & 36 & 43 & 15 & 22 & $4.8^{\mathrm{a}}$ & $4.9^{\mathrm{a}}$ & $1.8^{\mathrm{a}}$ & $2.0^{\mathrm{a}}$ \\
\hline Garrido [37] & 51.1 & 51.5 & 12.4 & 19 & $7.62^{\mathrm{b}}$ & $8.06^{\mathrm{b}}$ & $1.79^{\mathrm{b}}$ & $3.38^{\mathrm{b}}$ \\
\hline Gornet [38] & $55.5 \pm 14.7$ & $56.4 \pm 15.9$ & $16^{\mathrm{a}}$ & $24^{\mathrm{a}}$ & $6.07 \pm 2.08^{b}$ & $6.93 \pm 2.15^{\mathrm{b}}$ & $1.0^{\mathrm{a} b}$ & $1.9^{\mathrm{a} b}$ \\
\hline Grasso [39] & $21 \pm 2.1$ & $20.2 \pm 6.4$ & $5.4 \pm 2.1$ & $5.2 \pm 3.2$ & $7.02 \pm 0.64^{b}$ & $7.1 \pm 0.59^{b}$ & $1.03 \pm 0.27^{b}$ & $1.07 \pm 0.21^{\mathrm{b}}$ \\
\hline Hisey [40] & $55^{\mathrm{a}}$ & $55^{\mathrm{a}}$ & $17^{\mathrm{a}}$ & $18.5^{\mathrm{a}}$ & $7.1^{\mathrm{ab}}$ & $7.0^{\mathrm{a} b}$ & $1.8^{\mathrm{ab}}$ & $2.0^{\mathrm{a} b}$ \\
\hline Hou [41] & $49.8 \pm 19.7$ & $51.2 \pm 17.3$ & $17.2 \pm 13.4$ & $18.3 \pm 11.4$ & $8.1 \pm 1.1$ & $8.2 \pm 1.4$ & $2.6 \pm 1.0$ & $3.1 \pm 0.8$ \\
\hline Hacker [42] & NA & NA & NA & NA & $6.9^{\mathrm{ab}}$ & $6.6^{\mathrm{ab}}$ & NA & NA \\
\hline Jawahar [43] & 61 & 60 & 14 & 25 & $8.0^{\mathrm{b}}$ & $7.6^{\mathrm{b}}$ & $1.9^{\mathrm{b}}$ & $2.0^{\mathrm{b}}$ \\
\hline Kim [44] & $25.3 \pm 1.8$ & $25.5 \pm 1.5$ & $7.6 \pm 0.9$ & $7.2 \pm 1.6$ & $8.3 \pm 1.0$ & $8.3 \pm 0.9$ & $3.7 \pm 0.9$ & $3.8 \pm 1.1$ \\
\hline $\mathrm{Li}[45]$ & $19.8 \pm 7.2$ & $21.8 \pm 6.9$ & $5.8 \pm 2.9$ & $10.2 \pm 3.4$ & $5.74 \pm 1.58^{\mathrm{b}}$ & $5.97 \pm 1.67^{\mathrm{b}}$ & $1.16 \pm 1.09^{\mathrm{b}}$ & $1.32 \pm 1.17^{\mathrm{b}}$ \\
\hline Phillips [46] & $56^{\mathrm{a}}$ & $55^{\mathrm{a}}$ & $22^{\mathrm{a} *}$ & $26^{\mathrm{a}} *$ & 6.8 & 7.3 & $2.6^{\mathrm{a} b *}$ & $3.0^{\mathrm{ab}} *$ \\
\hline Porchet [47] & $54^{\mathrm{a}}$ & $60^{\mathrm{a}}$ & $11^{\mathrm{a}}$ & $23^{\mathrm{a}}$ & $6.8^{\mathrm{ab}}$ & $7.2^{\mathrm{a} b}$ & $2.2^{\mathrm{a} b}$ & $2.9^{\mathrm{ab}}$ \\
\hline \multicolumn{9}{|l|}{ Riew [48] } \\
\hline Prestige ST & $53.5 \pm 13.9$ & $53.5 \pm 16.9$ & $21.4 \pm 20.1$ & $22.4 \pm 22.2$ & $6.8^{\mathrm{ab}}$ & $6.8^{\mathrm{ab}}$ & $1.7^{\mathrm{ab}}$ & $1.5^{\mathrm{ab}}$ \\
\hline Bryan & $52.0 \pm 14.6$ & $50.8 \pm 18.8$ & $16.5 \pm 16.7 *$ & $29.9 \pm 26.3 *$ & $7.3^{\mathrm{ab}}$ & $7.5^{\mathrm{a} b}$ & $2.0^{\mathrm{a} b}$ & $4.3^{\mathrm{ab}}$ \\
\hline Riina [49] & $65.6 \pm 11.7$ & $60.2 \pm 11.7$ & $18.9 \pm 16.8$ & $22.3 \pm 13.5$ & $7.48 \pm 1.94^{b}$ & $7.16 \pm 2.60^{b}$ & $1.79 \pm 2.41^{b}$ & $1.74 \pm 2.21^{\mathrm{b}}$ \\
\hline Rožanković [50] & $50.90 \pm 11.48$ & $51.20 \pm 8.60$ & $11.60 \pm 4.44 *$ & $19.68 \pm 5.98 *$ & $7.56 \pm 1.36$ & $7.5 \pm 1.39$ & $2.36 \pm 0.75 *$ & $3.46 \pm 0.68 *$ \\
\hline Sasso [51] & 47 & 49 & 10 & 11 & $7.2^{\mathrm{b}}$ & $7.3^{\mathrm{b}}$ & $1.6^{\mathrm{b} *}$ & $3.2^{\mathrm{b}} *$ \\
\hline Sasso [52] & $51.4 \pm 15.3$ & $50.2 \pm 15.9$ & $16.2 \pm 18.5$ & $19.2 \pm 19.3$ & $7.54 \pm 1.99^{b}$ & $7.48 \pm 2.30^{\mathrm{b}}$ & $2.30 \pm 2.77^{b}$ & $3.03 \pm 3.97^{\mathrm{b}}$ \\
\hline Steinmetz [53] & 60.2 & 61.5 & $32^{\mathrm{a}}$ & $36^{\mathrm{a}}$ & $7.7 \pm 1.6$ & $8.0 \pm 1.8$ & $3.9 \pm 3.2$ & $3.9 \pm 2.6$ \\
\hline Vaccaro [54] & $51.8 \pm 13.84$ & $51.5 \pm 14.86$ & $13^{\mathrm{a}}$ & $17^{\mathrm{a}}$ & $6.52 \pm 2.68^{b}$ & $6.34 \pm 2.73^{\mathrm{b}}$ & $1.4^{\mathrm{ab}}$ & $2.0^{\mathrm{a} b}$ \\
\hline Wang [55] & $43.5 \pm 8.6$ & $45.4 \pm 7.6$ & $8.9 \pm 4.5$ & $8.4 \pm 5.1$ & $6.3 \pm 1.6$ & $6.4 \pm 1.2$ & $2.2 \pm 0.5$ & $2.4 \pm 0.6$ \\
\hline Yan [56] & $47.3 \pm 7.1$ & $48.6 \pm 6.8$ & $24.1 \pm 3.8^{c}$ & $23.8 \pm 3.6^{\mathrm{c}}$ & $\mathrm{NA}$ & NA & NA & NA \\
\hline Zhang [57] & $51.63 \pm 7.18$ & $54.53 \pm 8.47$ & $14.89 \pm 2.90$ & $15.25 \pm 3.77$ & $6.81 \pm 0.81^{b}$ & $6.88 \pm 0.71^{\mathrm{b}}$ & $1.91 \pm 0.50^{\mathrm{b}} *$ & $2.15 \pm 0.49^{\mathrm{b}} *$ \\
\hline
\end{tabular}

NDI (100-point scale) and VAS (10-point) scores at baseline and after 2 years for each study including both patients suffering from cervical radiculopathy or/and myelopathy

*Reported statistically significant difference

${ }^{a}$ The value is estimated from the figure in articles

${ }^{\mathrm{b}}$ This VAS score was based on the 100- or 20-point VAS and modified (divided by 10 or 2) to fit this comparison NA: information not available

${ }^{\mathrm{c}}$ Three-year follow-up results, as the 2-year follow-up was not available

\section{Complications in articles describing mixed patient populations}

Three articles report statistically significant differences in the incidence of complications; the first study found a higher incidence of device-related complications in the ACDF group [48], the second study reported a higher rate of overall adverse events in the ACDA group [38], and the third article found more severe adjacent-level radiographic changes in the ACDF group [33]. Two other articles studied ASD very specifically but couldn't find statistically significant differences between the two treatment strategies $[37,56]$. However, it should be noted that in both article types, the articles that report on ASD use different 
Table 7 Number of reoperations and ASD incidence

\begin{tabular}{|c|c|c|c|c|}
\hline \multirow[t]{2}{*}{ Study } & ACDA & $\mathrm{ACDF}$ & ACDA & $\mathrm{ACDF}$ \\
\hline & \multicolumn{2}{|c|}{ Reoperations } & \multicolumn{2}{|c|}{ ASD incidence } \\
\hline Coric [28] & $4 / 41$ & $1 / 32$ & NA & NA \\
\hline Index level & 1 & 0 & & \\
\hline Adjacent level & 2 & 1 & & \\
\hline Hou [24] & $1 / 51 *$ & $7 / 48 *$ & $1 / 51 *$ & $7 / 48 *$ \\
\hline Index level & 0 & NA & NA & NA \\
\hline Adjacent level & 1 & NA & NA & NA \\
\hline Janssen [21] & $13 / 103$ & $31 / 106$ & $1 / 103$ & $2 / 106$ \\
\hline Index level & 6 & 8 & NA & NA \\
\hline Index and adjacent level & 1 & 11 & NA & NA \\
\hline Adjacent level & 6 & 22 & NA & NA \\
\hline Nabhan [23] & $0 / 17$ & $1 / 24$ & $0 / 17$ & $1 / 24$ \\
\hline Index level & 0 & 0 & 0 & 0 \\
\hline Adjacent level & 0 & 1 & 0 & 1 \\
\hline $\begin{array}{l}\text { Park [26] } \\
\text { Index level } \\
\text { Adjacent level }\end{array}$ & NA & NA & NA & NA \\
\hline $\begin{array}{l}\text { Sala [27] } \\
\text { Index level } \\
\text { Adjacent level }\end{array}$ & NA & NA & NA & NA \\
\hline Sundseth [29] & $8 / 68^{*}$ & $1 / 68^{*}$ & NA & NA \\
\hline Index level & 8 & 1 & & \\
\hline Adjacent level & 0 & 0 & & \\
\hline Zhang [25] & $1 / 55^{\dagger}$ & $1 / 56^{\times}$ & $1 / 55^{\dagger}$ & $1 / 56^{\times}$ \\
\hline Index level & 0 & 0 & 0 & 0 \\
\hline Adjacent level & 1 & 1 & 1 & 1 \\
\hline
\end{tabular}

Number of reoperations and the level of reoperation in the left column and ASD incidence in number of patients/total number of patients in the treatment group

$N A$ information not available

*Reported statistically significant differences

${ }^{\dagger} \times{ }^{\times}$Concerning the same patient

diagnostic criteria for ASD. This could influence the reliability of the results and thus influence the comparability between articles that describe results on ASD.

\section{Heterogeneity}

Pooling results from the eight radiculopathy articles was considered; however, it was found that results were too heterogeneously reported for doing so. The number of studies was small, standard deviations were scarcely reported, p-values were mostly provided for the comparison between baseline and 2 years post-operatively within one treatment group instead of between the treatment group. Pooling the data would therefore require statistical imputation for the majority of the standard deviations and p-values. Articles were also clinically heterogeneous, as NDI and VAS scores were expressed on different scales and some articles reported the exact values after 2 years, while others reported the decline from baseline to 2 years or the difference between ACDA and ACDF at 2 years. Pooling results in mixed group articles has been done previously and is therefore likely not to lead to new insights [58-61]. Subsequently, this means that heterogeneity tests, such as the $I^{2}$, were not performed, as data were not pooled.

\section{Discussion}

Meticulous literature research reveals that pain and disability scores were comparable in patients after 2 years and not dependent on receiving either a cage or a prosthesis, after anterior cervical discectomy for radiculopathy. Likewise, no difference in outcome scores was found between these surgical interventions in mixed patient populations. The same was true for the reoperation rates and the incidence of adjacent segment degeneration (ASD). After using the GRADE approach, the level of evidence for absence of a difference in neck pain and disability in radiculopathy patients is higher than the level of evidence in the mixed patient population; however, the overall level of evidence was low. This conclusion is in line with a meta-analysis by Bartels from 2010, which demonstrates that most studies comparing ACDF and ACDA are not blinded and that a clinical benefit for the prosthesis is not proven [58].

Several other meta-analyses comparing ACDA and ACDF have been published [59-61]. These meta-analyses included mainly studies that did not exclude myelopathy patients. These patients are prone to have more severely degenerated cervical spines and perform different on outcome scales. It is therefore most striking that in this systematic review the mean NDI 2 years post-operatively is lower (better) in the ACDA group with both myelopathy and radiculopathy patients than in the ACDA group with radiculopathy patients. This phenomenon might suggest the presence of bias due to industry sponsoring or lack of blinding. An alternative hypothesis could be that patients with more degenerated cervical spines are used to a certain amount of pain and therefore are more likely to report a better disability or pain score.

This review was set up as a counterweight to the 21 meta-analyses retrieved from Bartels' article on studies comparing ACDF and ACDA concluding that outcome in prosthesis implanted patients was slightly better than in patients that underwent cervical fusion, although not statistically significant nor clinically relevant. It was hypothesized that outcome could be more convincingly favourable for the prosthesis if only radiculopathy patients would be considered. However, the opposite conclusion 
had to be drawn. Not only were the results in radiculopathy patients not different in ACDA and ACDF patients, but careful analysis of literature on mixed patient populations demonstrated that results were comparable in that patient population too. The suggestion that is offered by most of the existing articles, that the prosthesis is clinically superior to fusion, is therefore most likely to be too optimistic.

Another argument that is often used in favour of the prosthesis is claim of superior radiological results in terms of ASD and Range Of Motion (ROM). However, a recent systematic review shows no convincing radiological evidence for superiority of the prosthesis in ASD [62]. Additionally, the authors stress the absence of solid evidence for a correlation between the increased incidence of ASD and worse clinical outcome.

A limitation of the majority of the analysed studies is the use of a combined success score to define which treatment arm performs better. Apart from including an improvement in NDI or VAS score, most of these success scores added 'neurological success'. This means that an evaluation conducted by the investigator for muscle strength, sensory assessments and reflex assessments was included. These investigator-conducted evaluations are prone to bias as the articles do not mention whether or not the investigator was blinded to the treatment the patient received. When these combined success scores are not taken into account, but only the plain clinical outcome measures and their statistical significance and clinical relevance, the inevitable conclusion is that ACDA is not superior to ACDF.

Based on clinical outcome measures, literature indicates that the results of ACDF and ACDA do not differ in the treatment of cervical radiculopathy. The results are not prominently different in patients suffering from myelopathy with or without radiculopathy. Further research should have more statistical power, should apply specific inclusion criteria to increase the external validity to specific groups of patients, should blind both the patients and the outcome assessor and report long-term follow-up results in order to draw definitive conclusions on the clinical relevance of the prosthesis. With the increase in power, the possibility of performing an additional subgroup analyses should be considered to identify possible subgroups that might benefit more from receiving a prosthesis.

\section{Compliance with ethical standards}

Conflict of interest The authors declare that they have no conflict on interest.

Open Access This article is distributed under the terms of the Creative Commons Attribution 4.0 International License (http://creat ivecommons.org/licenses/by/4.0/), which permits unrestricted use, distribution, and reproduction in any medium, provided you give appropriate credit to the original author(s) and the source, provide a link to the Creative Commons license, and indicate if changes were made.

\section{References}

1. Robinson RA, Smith GW (1955) Anterolateral cervical disc removal and interbody fusion for cervical disc syndrome. Bull John Hopkins Hosp. 96:223-224

2. Cloward RB (1958) The anterior approach for ruptured cervical discs. J Neurosurg 15:602-614

3. Dereymaeker A, Mulier J: [Vertebral fusion by a ventral approach in cervical intervertebral disk disorders.] Rev Neurol. (Paris) 99:597-616, 19589 (Fr)

4. Robertson JT, Papadopoulos SM, Traynelis VC (2005) Assessment of adjacent-segment disease in patients treated with cervical fusion or arthroplasty: a prospective 2-year study. J Neurosurg Spine 3:417-423

5. Eck JC, Humphreys SC, Lim TH et al (2002) Biomechanical study on the effect of cervical spine fusion on adjacent-level intradiscal pressure and segmental motion. Spine 27:2431-2434

6. Bartels RHMA, Donk RD, Verhagen WIM, Hosman AJF, Verbeek ALM (2017) Reporting the results of meta-analyses: a plea for incorporating clinical relevance referring to an example. Spine $\mathbf{J}$ 17(11):1625-1632

7. Moher D, Liberati A, Tetzlaff J, Altman DG (2009) Preferred reporting items for systematic reviews and meta-analyses: the PRISMA statement. PLoS Med 6(7):e1000097

8. Form for quality assessment of a randomized controlled trial (RCT). Dutch Cochrane Quality Assessment. https://netherland s.cochrane.org/sites/netherlands.cochrane.org/files/public/uploa ds/4.4_rct_checklist.pdf. Accessed 18 Dec 2017

9. Carreon LY, Glassman SD, Campbell MJ, Anderson PA (2010) Neck Disability Index, short form-36 physical component summary, and pain scales for neck and arm pain: the minimum clinically important difference and substantial clinical benefit after cervical spine fusion. The Spine Journal 10(6):469-474

10. Vernon H, Mior S (1991) The Neck Disability Index: a study of reliability and validity. J Manipulative Physiol Ther 14(7):409-415

11. Auffinger BM, Lall RR, Dahdaleh NS, Wong AP, Lam SK, Koski $T$ et al (2013) Measuring surgical outcomes in cervical spondylotic myelopathy patients undergoing anterior cervical discectomy and fusion: assessment of minimum clinically important difference. PLoS ONE 8(6):e67408. https://doi.org/10.1371/journ al.pone.0067408

12. Lauche R, Langhorst J, Dobos GJ, Cramer H (2013) Clinically meaningful differences in pain, disability and quality of life for chronic nonspecific neck pain-a reanalysis of 4 randomized controlled trials of cupping therapy. Complement Ther Med 21(4):342-347. https://doi.org/10.1016/j.ctim.2013.04.005

13. Atkins D, Best D, Briss P, Eccles M, Falck-Ytter Y (2004) Grading quality of evidence and strength of recommendations. BMJ 328(7454): 1490

14. Furlan AD, Pennick V, Bombardier C, van Tulder M (2009) 2009 updated method guidelines for systematic reviews in the Cochrane Back Review Group. Spine 34(18):1929-1941

15. Burkus J, Traynelis V, Haid R, Mummaneni P (2014) Clinical and radiographic analysis of an artificial cervical disc: 7-year followup from the Prestige prospective randomized controlled clinical trial. J Neurosurg Spine 21(4):516-528

16. Burkus JK, Haid RW, Traynelis VC, Mummaneni PV (2010) Long-term clinical and radiographic outcomes of cervical disc replacement with the Prestige disc: results from a 
prospective randomized controlled clinical trial. J Neurosurg Spine 13:308-318

17. Delamarter R, Murrey D, Janssen M, Goldstein J, Zigler J, Tay B et al (2010) Results at 24 months from the prospective, randomized, multicenter Investigational Device Exemption trial of ProDisc-C versus anterior cervical discectomy and fusion with 4-year follow-up and continued access patients. SAS J 4(4):122-128

18. Murrey D, Janssen M, Delamarter R, Goldstein J, Zigler J, Tay B et al (2009) Results of the prospective, randomized, controlled multicenter Food and Drug Administration investigational device exemption study of the ProDisc-C total disc replacement versus anterior discectomy and fusion for the treatment of 1-level symptomatic cervical disc disease. Spine J 9(4):275-286

19. Zigler J, Delamarter R, Murrey D, Spivak J, Janssen M (2013) ProDisc-C and anterior cervical discectomy and fusion as surgical treatment for single-level cervical symptomatic degenerative disc disease. Spine 38(3):203-209

20. Loumeau T, Darden B, Kesman T, Odum S, Van Doren B, Laxer EB, Murrey D (2016) A RCT comparing 7-year clinical outcomes of one level symptomatic cervical disc disease (SCDD) following ProDisc-C total disc arthroplasty (TDA) versus anterior cervical discectomy and fusion (ACDF). Eur Spine J 25(7):2263-2270

21. Janssen M, Zigler J, Spivak J, Delamarter R, Darden B, Kopjar B (2015) ProDisc-C total disc replacement versus anterior cervical discectomy and fusion for single-level symptomatic cervical disc disease. J Bone Joint Surg 97(21):1738-1747

22. Nabhan A, Ahlhelm F, Shariat K, Pitzen T, Steimer O, Steudel W et al (2007) The ProDisc-C prothesis: clinical and radiological experience 1 year after surgery. Spine 32(18):1935-1941

23. Nabhan A, Steudel W, Pape D, Ishak B (2007) Segmental kinematics and adjacent level degeneration following disc replacement versus fusion: RCT with three years of follow-up. J Long Term Eff Med Implants 17(3):229-236

24. Hou Y, Nie L, Pan X, Si M, Han Y, Li J et al (2016) Effectiveness and safety of Mobi-C for treatment of single-level cervical disc spondylosis: a randomised control trial with a minimum of five years of follow-up. Bone Joint J 98B(6):829-833

25. Zhang H, Shao Y, Chen Y, Hou Y, Cheng L, Si M et al (2014) A prospective, randomised, controlled multicentre study comparing cervical disc replacement with anterior cervical decompression and fusion. Int Orthop 38(12):2533-2541

26. Park J, Roh K, Cho J, Ra Y, Rhim S, Noh S (2008) Comparative analysis of cervical arthroplasty using mobi-c ${ }^{\circledR}$ and anterior cervical discectomy and fusion using the solis ${ }^{\circledR}$-cage. J Korean Neurosurg Soc 44(4):217-221

27. Sala V, Lisi C, Di Natali G, Zanellato S, Dall'Angelo A, Tinelli C et al (2015) Functional and quality of life evaluation after single level cervical discectomy and fusion or cervical disc replacement. G Ital Med Lav 37(4):239-244

28. Coric D, Kim PK, Clemente JD, Boltes MO, Nussbaum M, James S (2013) Prospective randomized study of cervical arthroplasty and anterior cervical discectomy and fusion with long-term follow-up: results in 74 patients from a single site. J Neurosurg Spine 18(1):36-42

29. Sundseth J, Fredriksli O, Kolstad F, Johnsen L, Pripp A, Andresen $\mathrm{H}$ et al (2017) The Norwegian Cervical Arthroplasty Trial (NORCAT): 2-year clinical outcome after single-level cervical arthroplasty versus fusion - a prospective, single-blinded, randomized, controlled multicenter study. Eur Spine J 26:1225-1235

30. Cheng L, Nie L, Li M, Huo Y, Pan X (2011) Superiority of the bryan ${ }^{\circledR}$ disc prosthesis for cervical myelopathy: a randomized study with 3-year followup. Clin Orthop Relat Res 469(12):3408-3414
31. Coric D, Finger F, Boltes P (2006) Prospective randomized controlled study of the Bryan Cervical Disc: early clinical results from a single investigational site. J Neurosurg Spine 4(1):31-35

32. Coric D, Cassis J, Carew J, Boltes M (2010) Prospective study of cervical arthroplasty in 98 patients involved in 1 of 3 separate investigational device exemption studies from a single investigational site with a minimum 2-year follow-up. J Neurosurg Spine 13(6):715-721

33. Coric D, Nunley P, Guyer R, Musante D, Carmody C, Gordon C et al (2011) Prospective, randomized, multicenter study of cervical arthroplasty: 269 patients from the Kineflex|C artificial disc investigational device exemption study with a minimum 2-year follow-up. J Neurosurg Spine 15(4):348-358

34. Davis RJ, Nunley PD, Kim KD et al (2015) Two-level total disc replacement with Mobi-C cervical artificial disc versus anterior discectomy and fusion: a prospective, randomized, controlled multicenter clinical trial with 4-year follow-up results. J Neurosurg Spine 22:15-25

35. Ding C, Liu H, Hu T et al (2012) Clinical outcomes of Prestige LP cervical disc replacement a prospective controlled single site trail with 24-month follow up. Chin J Orthop 32:32-38

36. Fay LY, Huang WC, Tsai TY et al (2014) Differences between arthroplasty and anterior cervical fusion in two-level cervical degenerative disc disease. Eur Spine J 23:627-634

37. Garrido B, Taha T, Sasso R (2010) Clinical outcomes of bryan cervical disc arthroplasty a prospective, randomized, controlled, single site trial with 48-month follow-up. J Spinal Disord Tech 23(6):367-371

38. Gornet M, Burkus J, Shaffrey M, Nian H, Harrell F (2016) Cervical disc arthroplasty with prestige LP disc versus anterior cervical discectomy and fusion: seven-year outcomes. Int J Spine Surg 10:24

39. Grasso G (2015) Clinical and radiological features of hybrid surgery in multilevel cervical degenerative disc disease. Eur Spine J 24(Suppl 7):842-848

40. Hisey M, Zigler J, Jackson R, Nunley P, Bae H, Kim K et al (2016) Prospective, randomized comparison of one-level MobiC cervical total disc replacement vs anterior cervical discectomy and fusion: results at 5-year follow-up. Int J Spine Surg 10:10

41. Hou Y, Liu Y, Yuan W et al (2014) Cervical kinematics and radiological changes after discover artificial disc replacement versus fusion. Spine J 14:867-877

42. Hacker RJ (2005) Cervical disc arthroplasty: a controlled randomized prospective study with intermediate follow-up results. J Neurosurg Spine 3(6):424-428

43. Jawahar A, Cavanaugh DA, Kerr EJ, Birdsong EM, Nunley PD (2010) Total disc arthroplasty does not affect the incidence of adjacent segment degeneration in cervical spine: results of 93 patients in three prospective randomized clinical trials. Spine J 10:1043-1048

44. Kim SW, Limson MA, Kim SB et al (2009) Comparison of radiographic changes after ACDF versus Bryan disc arthroplasty in single and bi-level cases. Eur Spine J 18(2):218-231

45. Li Z, Yu S, Zhao Y, Hou S, Fu Q, Li F et al (2014) Clinical and radiologic comparison of dynamic cervical implant arthroplasty versus anterior cervical discectomy and fusion for the treatment of cervical degenerative disc disease. J Clin Neurosci 21(6):942-948

46. Phillips F, Geisler F, Gilder K, Reah C, Howell K, McAfee P (2015) Long-term outcomes of the US FDA IDE prospective, randomized controlled clinical trial comparing PCM cervical disc arthroplasty with anterior cervical discectomy and fusion. Spine 40(10):674-683

47. Porchet F, Metcalf NH (2004) Clinical outcomes with the Prestige II cervical disc: preliminary results from a prospective randomized clinical trial. Neurosurg Focus 17:E6 
48. Riew KD, Buchowski JM, Sasso R, Zdeblick T, Metcalf NH, Anderson PA (2008) Cervical disc arthroplasty compared with arthrodesis for the treatment of myelopathy. J Bone Joint Surg Am 90(11):2354-2364

49. Riina J, Patel A, Dietz JW, Hoskins JS, Trammell TR et al (2008) Comparison of single-level cervical fusion and a metal-on-metal cervical disc replacement device. Am J Orthop (Belle Mead NJ). 37:E71-E77

50. Rožanković M, Marasanov SM, Vukić M (2017) Cervical disk replacement with discover versus fusion in a single-level cervical disk disease: a prospective single-center randomized trial with a minimum 2-year follow-up. Clin Spine Surg 30(5):515-522

51. Sasso R, Smucker J, Hacker R, Heller J (2007) Clinical outcomes of BRYAN cervical disc arthroplasty: a prospective, randomized, controlled, multicenter trial with 24-month follow-up. J Spinal Disord Tech 20(7):481-491

52. Sasso RC, Anderson PA, Riew KD, Heller JG (2011) Results of cervical arthroplasty compared with anterior discectomy and fusion: four-year clinical outcomes in a prospective, randomized controlled trial. J Bone Joint Surg Am 93(18):1684-1692

53. Steinmetz M, Patel R, Traynelis V, Resnick D, Anderson P (2008) Cervical disc arthroplasty compared with fusion in a workers' compensation population. Neurosurgery 63(4):741-747

54. Vaccaro A, Beutler W, Peppelman W, Marzluff J, Highsmith J, Mugglin A et al (2013) Clinical outcomes with selectively constrained SECURE-C cervical disc arthroplasty. Spine 38(26):2227-2239

55. Wang Y, Cai B, Zhang XS et al (2008) Clinical outcomes of single level Bryan cervical disc arthroplasty: a prospective controlled study. Zhonghua Wai Ke Za Zhi 46:328-332

56. Yan S, Di J, Shen Y (2017) Adjacent segment degeneration following anterior cervical discectomy and fusion versus the bryan cervical disc arthroplasty. Med Sci Monit 23:2692-2700
57. Zhang X, Zhang X, Chen C, Zhang Y, Wang Z, Wang B et al (2012) Randomized, controlled, multicenter, clinical trial comparing BRYAN cervical disc arthroplasty with anterior cervical decompression and fusion in China. Spine 37(6):433-438

58. Bartels R, Donk R, Verbeek A (2010) No justification for cervical disc prostheses in clinical practice. Neurosurgery 66(6): 1153-1160

59. Gao F, Mao T, Sun W, Guo W, Wang Y, Li Z et al (2015) An updated meta-analysis comparing artificial cervical disc arthroplasty (CDA) versus anterior cervical discectomy and fusion (ACDF) for the treatment of cervical degenerative disc disease (CDDD). Spine 40(23):1816-1823

60. Wu A, Xu H, Mullinix K, Jin H, Huang Z, Lv Q et al (2015) Minimum 4-year outcomes of cervical total disc arthroplasty versus fusion; a meta-analysis based on prospective randomized controlled trials. Medicine 94(15):e665

61. Zhang Y, Liang C, Tao Y, Zhou X, Li H, Li F et al (2015) Cervical total disc replacement is superior to anterior cervical decompression and fusion: a meta-analysis of prospective randomized controlled trials. PLoS ONE 10(3):e0117826

62. Yang X, Janssen T, Arts MP, Peul WC, Vleggeert-Lankamp CLA (2018) Radiological follow-up after implanting cervical disc prosthesis in anterior discectomy: a systematic review. Spine J. 18(9):1678-1693. https://doi.org/10.1016/j.spinee.2018.04.021

Publisher's Note Springer Nature remains neutral with regard to jurisdictional claims in published maps and institutional affiliations. 